\title{
Morphological and Morphometric Evaluation of Mandibular Coronoid Process, Condylar Process and Mandibular Ramus in Jharkhand and Bihar Population
}

\author{
Nand Kishor Karmali ${ }^{1}$, Keshav Krishna ${ }^{2}$, Rajesh R. ${ }^{3}$, Rajiv Kumar Lal ${ }^{4}$, \\ Subhash Modi ${ }^{5}$
}

\author{
${ }^{1}$ Assistant Professor, ${ }^{2}$ Tutor, ${ }^{3}$ Associate Professor, \\ Department of Anatomy, Phulo Jhano Medical College, Dumka, Jharkhand, India \\ ${ }^{4}$ Tutor, Jawaharlal Nehru Medical College, Bhagalpur, Bihar, India. \\ ${ }^{5}$ Tutor, Mahatma Gandhi Memorial Medical College, Jamshedpur, Jharkhand, India
}

Corresponding Author: Subhash Modi

DOI: https://doi.org/10.52403/ijrr.20220203

\begin{abstract}
Background: Coronoid process of mandible gives attachment to temporalis and masseter muscles. The shape and size of coronoid process varies widely due to influence of many factors. Its shape has been described as triangular, hook shaped and rounded in various studies. Mandibular Condyle, is the part of the mandible that articulates with the temporal bones articular fossa and its appearance is influenced by various factors. The superior border of the mandible's ramus is formed by the mandibular notch and its contour is influenced by shape of the Coronoid process and the Mandibular condyle. Knowledge of these morphological variations is of great help to anthropologists, maxillofacial surgeons and forensic experts.

Aim: Aim of present study is the morphological differences in Coronoid process, Condylar process, and Mandibular Notch in adult dry human mandibles in Jharkhand and Bihar.

Material and method: 100 dry adult Mandible of known sex from the Department of Anatomy, Phulo-Jhano Medical College Dumka, Jharkhand and other medical colleges of Jharkhand and Bihar were studied. Shape of the coronoid process was visually assessed. Length of the coronoid process and mandibular process were measured by employing standardized method, using digital Vernier calliper.
\end{abstract}

Results: The triangular (120) shape of the coronoid process was the most common among the 200 sides, with $72(60 \%)$ on the right side and $48(40 \%)$ on the left. The second was beakshaped (68), with 36 (52.9 percent) on the right side and 32 (47 percent) on the left side, followed by the round shape (12), of which 7 $(58.4 \%)$ were on the right side and $5(41.6 \%)$ on the left side. Mean length of right and left side of coronoid process among male was 17.79 $\pm 0.88 \mathrm{~mm}$ and $17.51 \pm 0.83 \mathrm{~mm}$ respectively, while in females these measurements were $16.59 \pm 0.97 \mathrm{~mm}$ and $16.33 \pm 0.68 \mathrm{~mm}$ respectively. Mean length of right and left side of mandibular condyle among male was $12.9 \pm$ $2.13 \mathrm{~mm}$ and $10.88 \pm 2.01 \mathrm{~mm}$ respectively, while in females this value was $11.8 \pm 1.67 \mathrm{~mm}$ and $11.21 \pm 1.75 \mathrm{~mm}$ respectively. Average distance from the head of the mandible to the base of the mandible on right and left sides were64.22 \pm 5.77 $\mathrm{mm}$ and $64.05 \pm 5.92 \mathrm{~mm}$ respectively. Similarly values for distance from the base of the mandible to mandibular notch were $46.32 \pm 7.21 \mathrm{~mm}$ and $46.24 \pm 8.49 \mathrm{~mm}$ respectively and values for distance from the anterior border to the posterior border of the ramus of mandible were $30.48 \pm 2.36 \mathrm{mmand} 30.31 \pm 2.32 \mathrm{~mm}$ on right and left side respectively.

Conclusion: Triangular shape of coronoid process was most common type seen in Jharkhand and Bihar population. This finding is similar to many other such studies. There was 
statistically significant difference between length of coronoid process and mandibular condyle of male and female. All these findings are of immense importance to anthropologists, maxillofacial reconstructive surgeons and forensic experts.

Keywords: Morphology, Morphometry, Coronoid, Condyloid, sigmoid notch, Mandible.

\section{INTRODUCTION}

Mandible is the largest and strongest bone of the face. It has two processes: the Coronoid and the condylar. The Coronoid process is a thin flat triangular structure that projects upwards and slightly forwards from mandibular ramus and gives attachments to temporalis muscle from its margins and medial surface. Its lateral surface provides attachment to anterior fibres of masseter ${ }^{[1]}$. The Mandibular notch also known as sigmoid notch is the space between these two processes[2]. The size and shape of the Coronoid process varies. Dietary habits, hormones, genetic makeup, and the activity of the temporalis muscle all influence it[3]. Previous researchers have described multiple types of coronoid processes in adult human mandibles, including triangular, hook-shaped, and rounded coronoid processes, as opposed to the typical 'crows' beak' pattern[4,5]. Changes in the curvature of the process were interpreted as a sign of aging. Activity of Muscle and bone may vigorously affect the functions of each other and lead to altered morphology of the bone concerned[6].

The Mandibular Condyle, also known as the condyloid process, is the part of the mandible that articulates with the temporal bone's articular fossa. The appearance of the mandibular condyle varies significantly depending on age of the individual. Developmental variations, malocclusion, trauma, remodelling, endocrine disturbances, and a variety of other diseases affecting bones can all cause morphologic changes [7]. The superior border of the mandible's ramus is formed by the mandibular notch or mandibular incisure, which is directed upwards and vaguely backwards. The masseteric nerve, artery, and vein all pass through this area [8].

The shape of the Coronoid process and the Mandibular condyle influence the contour of the Mandibular Notch. The profiles of these structures are useful in forensic and anthropological studies of human sex identification because they show sexual dimorphism[9]. The coronoid process of the mandible has been used as a graft for the reconstruction of osseous defects in oral and facio-maxillary surgeries[10]. The coronoid process is also used to estimate age, gender, race, and species. Furthermore, anthropological descriptions of human mandibles show that differences in the shape of the condylar and coronoid processes are among the most striking differences between human races[11]. The morphology of the mandible is influenced by the individual's race, sex, ethnicity, dietary habits, and genetic constitution [12,13]. Therefore, the goal of this study is to look into the morphological differences in adult dry mandibles in Jharkhand and Bihar, specifically the Coronoid process, Condylar process, and Mandibular Notch.

The findings of this study will be useful in reconstruction of orbital floor deformities as in mucormycosis infection, trauma, tumours, temporomandibular joint ankylosis, and facial paralysis and for the treatment of chronic mandibular dislocations. In simple terms, the detailed morphology of the mandibular notch, coronoid, and condylar processes may provide a wealth of information to maxillofacial surgeons, anthropologists, ENT specialists, eye surgeons, and forensic experts.

\section{MATERIALS AND METHODS}

100 dry adult Mandible of known sex were collected from the Department of Anatomy, Phulo-Jhano Medical College Dumka, Jharkhand, Department of Anatomy, Mahatma Gandhi Memorial Medical College, Jamshedpur, Jharkhand, 
India and Department of Anatomy, Jawaharlal Nehru Medical College Bhagalpur, Bihar, were used for this study. There were no fractures, developmental anomalies, or pathological deformations in the mandibles that were chosen. This study excluded edentulous and young mandibles.

The following parameters were assessed for the morphometry of ramus of mandible using a Vernier calliper. 1.The lengthfrom the base of mandible to the highest point of the head of mandible.2. Length from the base of mandible to the centre of mandibular notch and 3 . The maximum breadth of ramus from anterior edge of ramus to posterior edge of ramus at the occlusal plane (Fig:1).
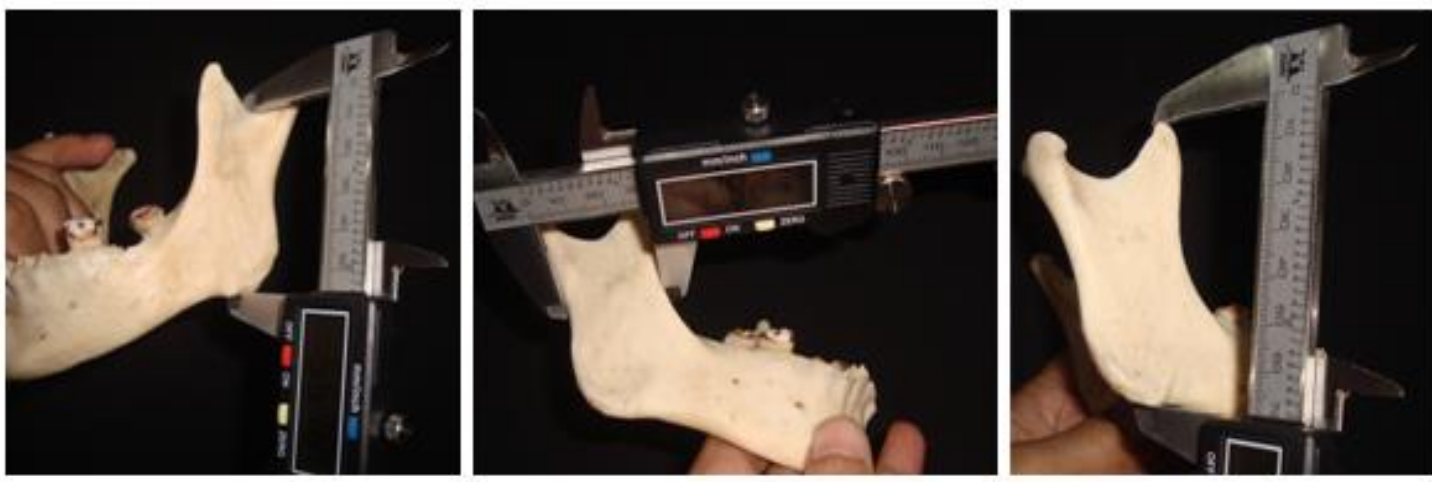

Fig.1: Morphometry of the Ramus of the mandible

To measure the size of the coronoid process, a point was marked on the lowermost point of the mandibular notch (A). From this point, a horizontal line was drawn in front and behind it, and another point was marked on the anterior (B) and posterior $(\mathrm{C})$ borders of the ramus of the mandible. At the tip of the coronoid process (D), a point was marked. Two lines were drawn connecting $\mathrm{B} \& \mathrm{D}$ and $\mathrm{A} \& \mathrm{D}$. The lengths of all three sides and the height of the perpendicular (E) were measured and compared from this triangle BDA (Fig:2).

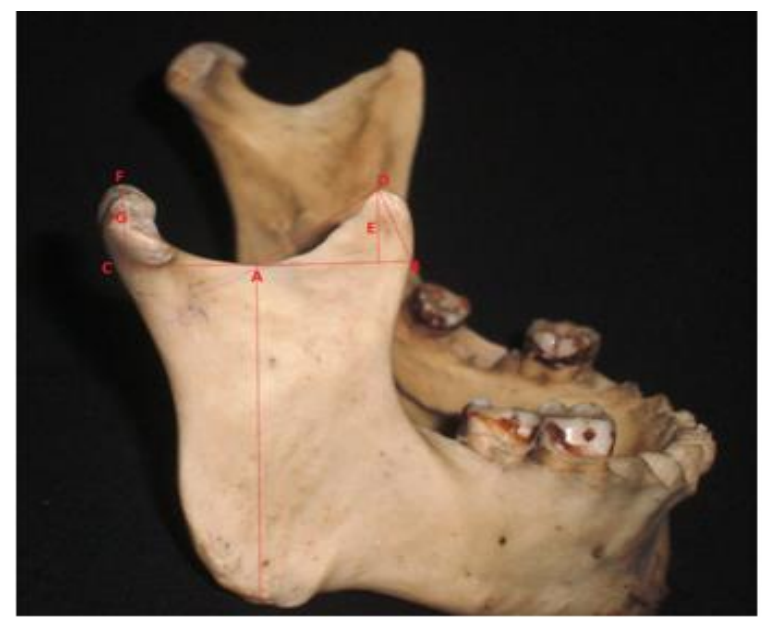

Fig. 2: Morphometry of coronoid and condyloid process
The length of the condyloid process was measured by making a point on the tip of the condyloid process (F). The line connecting the points ' $\mathrm{A}$ ' and ' $\mathrm{C}$ ' to $\mathrm{F}$ was drawn as a perpendicular. The length of the coronoid process was determined by the length of the perpendicular $(\mathrm{G})$.

All values were expressed in Mean \pm Standard Deviation. The paired ' $t$ ' test was used to compare the mean values of the right and left sides of the mandible. Pvalue $<0.05$ was considered statistically significant.

\section{OBSERVATIONS AND RESULTS \\ 3.1. Shape of the coronoid process}

In this study, 55 of the 100 mandibles belonged to male, while 45 belonged to female. The triangular (120) shape of the coronoid process was the most common among the 200 sides, with 72 $(60 \%)$ on the right side and $48(40 \%)$ on the left. The second was beak-shaped (68), with 36 (52.9 percent) on the right side and 32 (47 percent) on the left side, followed by the round shape (12), of which $7(58.4 \%)$ were on the right side and $5(41.6 \%)$ on the left side. 


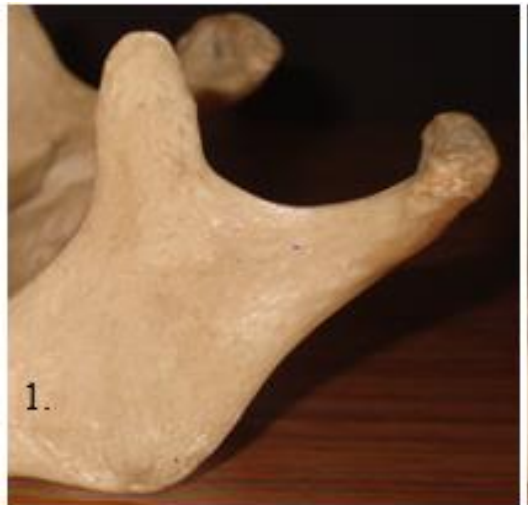

1.Rounded,

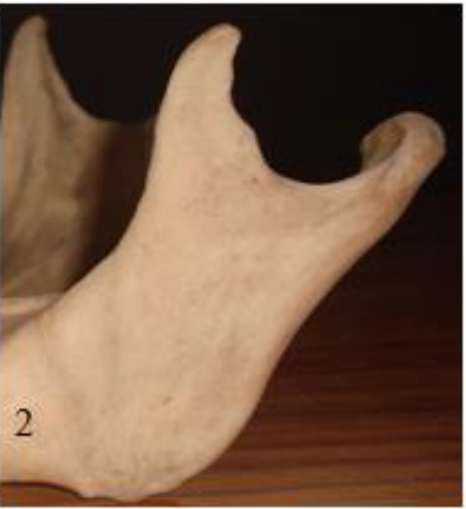

2. Hook shaped

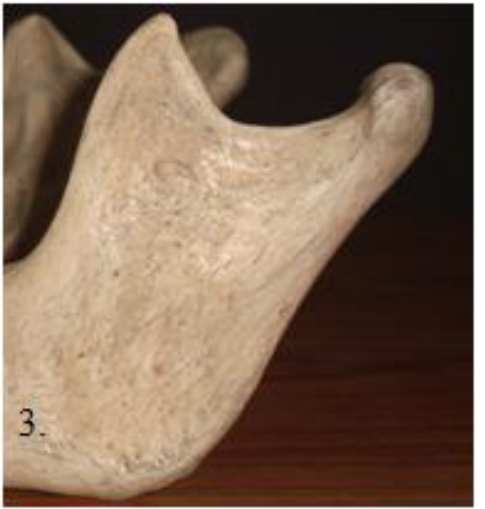

3.Triangular

Fig: 3. Shapes of coronoid process

Table1: Shape of coronoid process of mandible

\begin{tabular}{|l|c|c|c|}
\hline Shape of coronoid process & Total Number & Right & Left \\
\hline Triangular & $120(60 \%)$ & $72(60 \%)$ & $48(40 \%)$ \\
\hline Hook shaped / beak shaped & $68(34 \%)$ & $36(52.9 \%)$ & $32(47.1 \%)$ \\
\hline Rounded & $12(6 \%)$ & $07(58.4 \%)$ & $5(41.6 \%)$ \\
\hline
\end{tabular}

\subsection{Length of the coronoid process}

Table 2 shows the length of the coronoid process. The length of the coronoid process was determined by the length of the perpendicular, i.e., DE (Fig. 4). In general, the dimensions on the left side were smaller than those on the right, but this was statistically insignificant. The mean length of the coronoid process of the mandible was shorter in females than in males, and this difference was statistically significant $(\mathrm{p}<0.05)$.

Table 2: Length of the coronoid process

\begin{tabular}{|c|c|c|c|c|c|}
\hline \multicolumn{3}{|c|}{ In Males (Average in mm) } & \multicolumn{3}{c|}{ In females (Average in mm) } \\
\hline Side & Right & Left & Side & Right & Left \\
\hline AB & $19.88 \pm 1.23$ & $19.74 \pm .0 .92$ & AB & $18.98 \pm 0.95$ & $16.94 \pm 0.90^{*}$ \\
\hline BD & $19.53 \pm 1.13^{*}$ & $19.38 \pm 1.1$ & BD & $18.53 \pm 1.1^{*}$ & $18.23 \pm 0.972^{*}$ \\
\hline DA & $20.21 \pm 1.31$ & $20.02 \pm 1.43$ & DA & $19.34 \pm 0.89^{*}$ & $19.02 \pm .87^{*}$ \\
\hline DE & $17.79 \pm 0.88^{*}$ & $17.51 \pm 0.83$ & DE & $16.59 \pm 0.97 *$ & $16.33 \pm 0.68^{*}$ \\
\hline
\end{tabular}

\subsection{Length of the condyloid process}

The mean length of the condyloid process was longer in males than in females (Table 3), and this difference was statistically significant $(\mathrm{p}<0.05)$. In both males and females, the length of the right condyloid process appeared to be greater than that of the left (table no 3).

Table 3: Length of the condyloid process (in mm)
\begin{tabular}{|l|c|c|c|c|}
\hline \multirow{2}{*}{ Parameter } & \multicolumn{2}{|c|}{ Males } & \multicolumn{2}{c|}{ Females } \\
\cline { 2 - 5 } & Right side & Left side & Right side & Left side \\
\hline Length & $12.9 \pm 2.13$ & $10.88 \pm 2.01$ & $11.8 \pm 1.67^{*}$ & $11.21 \pm 1.75^{*}$ \\
\hline
\end{tabular}
All values are expressed as Mean \pm SD. $*$ denotes statistical significance $(\mathrm{p}<0.05)$

\subsection{Morphometry of Mandibular ramus}

The Distance from the head of the mandible to the base of the mandible in the right side $(64.22 \pm 5.77)$ was slightly greater than the left side $(64.05 \pm 5.92)$. The distance from the base of the mandible to the mandibular notch and the distance from the anterior to the posterior border of the ramus were greater on the right side than on the left (Table: 4)).

Table 4: Morphometry of the mandibular ramus (in $\mathrm{mm}$ )

\begin{tabular}{|l|l|l|}
\hline \multicolumn{1}{|c|}{ Variables } & Right side & \multicolumn{1}{c|}{ Left side } \\
\hline Distance from the head of the mandible to the base of the mandible & $64.22 \pm 5.77$ & $64.05 \pm 5.92$ \\
\hline Distance from the base of the mandible to mandibular notch & $46.32 \pm 7.21$ & $46.24 \pm 8.49$ \\
\hline Distance from the anterior border to the posterior border of the ramus of mandible & $30.48 \pm 2.36$ & $30.31 \pm 2.32$ \\
\hline
\end{tabular}

All values are expressed as Mean $\pm S D$. ${ }^{*}$ denotes statistical significance $(p<0.05)$ 


\section{DISCUSSION}

In the current study, we found differences in mandibular morphology in adult mandibles from the Bihar and Jharkhand populations. Previous researchers have reported various types of mandibular coronoid processes (Table 5). The majority of researchers reported that triangular shaped processes were the most common, followed by hook shaped processes and then round shaped processes. The findings of our study corroborated their observations. Whereas Bakirci et al. reported that the most common type of coronoid process is hookshaped coronoid process (60 percent).

Table 5: Comparative study of different shapes of coronoid process expressed as percentage (\%)

\begin{tabular}{|c|l|c|c|c|c|}
\hline S.No. & \multicolumn{1}{|c|}{ Author } & Year of study & Triangular shape & Hook shape & Round shape \\
\hline 1. & Issac\&Holla[14] & 2001 & 49.00 & 27.40 & 23.60 \\
\hline 2. & Varalakshmi KL et al.[15] & 2004 & 45.19 & 33.65 & 21.5 \\
\hline 3. & Khan et al.[16] & 2011 & 67.00 & 30.00 & 03.00 \\
\hline 4. & Hossain et al.[17] & 2011 & 29.65 & 45.00 & 25.35 \\
\hline 5. & Mahajan et al.[18] & 2012 & 48.70 & 27.40 & 23.78 \\
\hline 6. & Bakirci et al.[19] & 2013 & 20.00 & 60.00 & 20.00 \\
\hline 7. & Pradhan S et al.[20] & 2014 & 46.73 & 35.3 & 17.93 \\
\hline 8. & Gindha GS et al. [21] & 2015 & 61.00 & 25.5 & 13.50 \\
\hline 9. & Jadhav DS et al.[22] & 2017 & 60.76 & 23.84 & 15.38 \\
\hline 10. & Gaur NL et al.[23] & 2019 & 62.15 & 9.37 & 28.12 \\
\hline 11. & Present Study & 2022 & 60.00 & 34.00 & 12.00 \\
\hline
\end{tabular}

Table 6: Comparative study of Average Length of Coronoid process (in mm)

\begin{tabular}{|l|c|c|c|c|}
\hline \multirow{2}{*}{\multicolumn{1}{c|}{ Authors }} & \multicolumn{2}{c|}{ Males } & \multicolumn{2}{c|}{ Females } \\
\cline { 2 - 5 } & Right & Left & Right & Left \\
\hline Gindha GS et al.[21] & 18 & 17 & 17 & 16.20 \\
\hline Kahlon S et al.[24] & \multicolumn{4}{|c|}{ Overall average: 12.53} \\
\hline Kasat PA et al.[25] & \multicolumn{4}{|c|}{ Right: $18.2 \pm 3.44$, Left: $18 \pm 3.36$} \\
\hline Subbaramaiah M[26] & $14.9 \pm 0.37$ & $13.1 \pm 0.34$ & $15.1 \pm 0.33$ & $12.6 \pm 0.34$ \\
\hline Present study & $17.79 \pm 0.88$ & $17.51 \pm 0.83$ & $16.59 \pm 0.97$ & $16.33 \pm 0.68$ \\
\hline
\end{tabular}

In the current study, we found a statistically significant difference in the length of the coronoid processes of male and female mandibles, with the right-side coronoid process being significantly longer than the left. The obtained results were consistent with the findings of Gindha GS et al. and Kasat PA et al, who reported that the average length of the right-side coronoid process is greater than the left side and that male coronoid processes appear longer than female coronoid processes. Subbaramaiah $\mathrm{M}$ and Kahlon $\mathrm{S}$ et al. reported significantly lower values than the current study, with an average length ranging from 12.53 to 15.1 .

In our study, the mean measurement from the base of mandible to the highest point of the head of mandible was $64.22 \pm 5.77$ on the right side and $64.05 \pm$ $5.92 \mathrm{~mm}$ on the left side. The current finding agrees with Deepa G and Shrikrishna B.H [27], Rai et al [28], and Mesbahul Hoque et al [29], but differs from Saini et al. [30] and Rosa et al [31].
In this study, the mean measurement from base of the mandible to the mandibular notch was $46.32 \pm 7.21 \mathrm{~mm}$ on the right side and $46.24 \pm 8.49 \mathrm{~mm}$ on the left side. This finding of the current study is consistent with Jerolimov et al. [32] and Mesbahul Hoque et al [29] but differed from Keros et al [33] and Deepa $G$ and Shrikrishna B $\mathrm{H}[27]$.

In this study, the distance between the anterior and posterior edges of the ramus, which corresponded to its width, was. $48 \pm 2.36 \mathrm{~mm}$ on the right side and $30.31 \pm 2.32 \mathrm{~mm}$ on the left side. These findings are consistent with those of Keros et al. [33], Jerolimov et al. [32], Oguz and Bozkir [34], Kilarkaje et al. [35], Ennes and Medeiros [36], and Mesbahul Hoque et al [29], Deepa G and Shrikrishna B H [27].

\section{CONCLUSION}

Present study concluded with Triangular shape of coronoid process was the most common type seen in Jharkhand and Bihar population. This was followed by 
beak and rounded shape. This finding was similar to many other such studies. There was statistically significant difference between length of coronoid process and mandibular condyle of male and female in this study. All these findings along with other measurements of mandibular ramus are of immense importance to anthropologists, maxillofacial reconstructive surgeons and forensic experts.

\section{Acknowledgement: None}

\section{Conflict of Interest: None}

\section{Source of Funding: None}

\section{Ethical Approval: Approved}

\section{REFERENCES}

1. Standring, S. Gray's Anatomy. The Anatomical basis of Clinical Practice. Reprinted International $40^{\text {th }}$ Edition. Chapter-Mandible. Churchill Livingstone Elsevier. London (UK). (2011); page: 480 \& 532.

2. Harrison, RJ. Cunningham's Text Book of Anatomy. Reprinted 12th edition. Chapter bones, the mandible. Oxford University Press. Oxford, New York, Toronto; page: 127.

3. Nayak, Sunita, et al. "Study of the size of the coronoid process of mandible." IOSR J Dent Med Sci 14.6 (2015): 66-69.

4. Hossain, SM Akram, SM Moshadeq Hossain, and Fakhrul Amin Mohammad Hasanul Banna. "Variations in the Shape of the Coronoid process in the Adult Human Mandible." Bangladesh journal of anatomy 9.2 (2011): 75-78.

5. Prajapati, Vipul P., Ojaswini Malukar, and S. K. Nagar. "Variations in the morphological appearance of the coronoid process of human mandible." Nat J Med Res 1.2 (2011): 64-66.

6. Kiliaridis, Stavros. "Masticatory muscle influence on craniofacial growth." Acta Odontologica Scandinavica 53.3 (1995): 196-202.

7. Hegde, Shruthi, B. N. Praveen, and Shishir Ram Shetty. "Morphological and radiological variations of mandibular condyles in health and diseases: a systematic review." Dentistry 3.1 (2013): 154.

8. Breeland G, Aktar A, Patel BC. Anatomy, Head and Neck, Mandible. 2021 Jun 18. In: StatPearls [Internet]. Treasure Island (FL): StatPearls Publishing; 2022 Jan. PMID: 30335325.

9. Tassoker, Melek, et al. "Evaluation of mandibular notch, coronoid process, and mandibular condyle configurations with cone beam computed tomography." Biomed. Res.(India), 28 (19) (2017):832735.

10. Sabhlok, Samrat, Pushkar P. Waknis, and Kiran S. Gadre. "Applications of coronoid process as a bone graft in maxillofacial surgery." Journal of Craniofacial Surgery 25.2 (2014): 577-580.

11. Tapas, Smita. "Morphological variations of coronoid process in dry adult human mandibles." Indian J Basic Appl Med Res 3.March (2) (2014): 401-405.

12. Laird, Myra F., Callum F. Ross, and Paul O'Higgins. "Jaw kinematics and mandibular morphology in humans." Journal of human evolution 139 (2020): 102639.

13. Hirst, Cara Stella. How has the morphology of the human mandible varied in response to the dietary changes that have occurred in Britain between the Neolithic and PostMedieval periods?. Diss. UCL (University College London), 2019.

14. Issac, B; Holla, SJ. Variations in the shape of the coronoid process in the adult human mandible. J Anat. Soc. India. (2001); 50 (2): $137-139$.

15. Dr.Varalakshmi K. L. Dr.Padmavathi, G. And Dr. Sangeeta, variations in the shapes of coronoid process of mandible: an osteological study. International Journal of Recent Scientific Research Vol. 10, Issue, 01(C), pp. 30332-30334, January, 2019.

16. Khan, T.A. H.S; Sharieff, J.H. Observation on Morphological Features of Human Mandible. In 200 South Indian Subjects. Anatomica Karnataka. (2011); 5: 44 - 49.

17. Hossain, SMA; Hossain, SMM; Banna, FAMH. Variations in the Shape of the Coronoid process in the Adult Human Mandible. Bang J of Anat. (2011); 9 (2): 75 -78 .

18. Mahajan, A; Seema; Batra, APS; Khurana, BS; Gandhi, D. Variations in the shapes of Coronoid Process in Adult Human Mandible. J of Life Sci. (2012); 9: 29-33. 
19. Bakirci, S; Ari, Ilknur; Kafa, IM. Morphometric Characteristics and Typology of the Coronoid process of the Mandible. Acta Medica Medterranea. (2013); 29: 683686.

20. PradhanS et al. Anatomical Study of Various Shapes of Mandibular Coronoid Process in Relation to Gender \& Age. IOSR Journal of Dental and Medical Sciences (IOSR-JDMS) e-ISSN: 2279-0853, p-ISSN: 2279-0861. Volume 13, Issue 8 Ver. II (Aug. 2014), PP 09-14.

21. Gurbachan Singh Gindha et al, Morphometric Study of The Coronoid Process Of The Mandible For Its Various Shapes and Sexing Of The Mandible (A Dry Human Bone Study), Indo American $\mathrm{J}$ of Pharm Sci, 2015;2(6).

22. Dhanaji S Jadhav, Shashank B Vedpathak. Variations in the shapes of the coronoid process of adult human mandible in Marathwada and Western Maharashtra region. MedPulse-International Journal of Anatomy. November 2017; 4(2): 17-19.

23. Gaur Natwar Lal et al. Anatomical Study Of Various Shapes Of The Coronoid Process Of Human Mandible, International Journal of Recent Scientific Research Vol. 10, Issue, 01(C), pp. 30332-30334, January, 2019

24. Kasat PA et al. A study on coronoid process of the dry adult human mandibles. Journal of the Anatomical Society of India. Volume 65, Issue 1, June 2016, Pages 9-14. https://doi.org/10.1016/j.jasi.2016.07.007.

25. Kahlon S, Agnihotri G, Variations in mandibular coronoid process-A morphometric treatise. J Dent Spec 2020;8 (1):9-12

26. Subbaramaiah, M., Roshni Bajpe, S. R. Jagannatha and K. S. Jayanthi. "A Study of Various Forms of Mandibular Coronoid Process in Determination of Sex." Indian Journal of Clinical Anatomy and Physiology 2 (2015): 199-203.

27. Deepa, G., \& Shrikrishna, B.H. (2016). Morphometric Analysis of Dry Adult Human Mandibular Ramus. Indian Journal of Anatomy, 5, 179-183.

28. Rai R, Ranade AV, Prabhu LV, Pai MM, Madhyastha S, Kumaran M. A pilot study of the mandibular angle and ramus in Indian population. Int J Morphol. 2007; 25(2): 35356.

29. Md. Mesbahul Hoque et al. Morphometric Analysis of Dry Adult Human Mandibular Ramus. Bangladesh Journal of Anatomy. 2014; 12(1): 14-16.

30. Saini V, Srivastava R, Rai RK, Shamal SN, Singh TB, Tripathi SK. Mandibular ramus : an indicator for sex in fragmentary mandible. J. forensic Sci. 2011; 56(1): 1316.

31. Rosa MA, Reimers EG, Fregel R, Vazquez JV, Darias TD, Gonzalez MA, Larruga JM. Canary Island aborigin sex determination based on mandible parameters contrasted by amelogenin analysis. Journal of Archaeological Science. 2006; 1-8.

32. Jerolimov V, Kobler P, Keros J, Stanicic T, Bagic I.Assessment of position of foramen mandibulae in recent adult population. Coll. Antropol. 1998; 22(1):169-77.

33. Keros NJ, Panduric J, Buntak KD. Some anatomical and anthropological measures of mandibular ramusin our population. Coll.Antropol. 1997; 21(1): 203-10.

34. Oguz O, Bozkir MG. Evaluation of the location of the mandibular and mental foramina in dry, young, adult human male, dentulous mandibles. West Indian Med. J 2002; 51(1): 6-14.

35. Kilarkaje N, Nayak SR, Narayan P, Prabhu LV. The location of the mandibular foramen maintains absolute bilateral symmetry in mandibles of different age-groups. Hong Kong Dental Journal. 2005; 2: 35-37.

36. Ennes JP, Medeiros RM. Localization of Mandibular foramen and clinical Implications. Int. J. Morphol 2009; 27(4): 1305-11.

How to cite this article: Karmali NK, Krishna K, Rajesh R. et.al. Morphological and morphometric evaluation of mandibular coronoid process, condylar process and mandibular ramus in Jharkhand and Bihar population. International Journal of Research and Review. 2022; 9(2): 10-16. DOI: https:// doi.org/10.52403/ijrr.20220203 